\section{No Shortage of Engineers}

\section{To the Editor:}

I obtained the September issue of the MRS Bulletin from a friend. I am so glad I $\mathrm{did}$. The articles concerning materials education were excellent, but one specifically discussed a topic that has interested me for two years. Dr. Rustum Roy's article very clearly pointed out that the engineering "shortage" is "hype." I read the paragraph containing this previously hushed-up fact with great relief. Finally, someone of national renown had blown the cover off one of the most insidious lies our country's government and industry have perpetrated over the past ten years. THERE IS NO SHORTAGE OF ENGINEERS!

I graduated with a $P h D$ in engineering in December of 1990 and was out of work for eight months. I sent out over 150 resumes to industries and universities all over the country. I found to my amazement that there were as many as 300 applicants for the university positions! And yes, most of them were from noncitizens. During the 1980s, the American university system, in order to support itself, gladly accepted thousands of graduate-student applications from foreign students. The reasoning was valid (we currently stand by similar reasoning at my present place of employment!); there are no American graduate students. However, to purport that the reason for accepting foreign graduate students is because we need so many more postgraduate-level engineers because there is a shortage is simply not true! Why has there been a covert hush-up of this fact? Because with a greater supply, demand goes down. Industry now has a plenitude of excellent postgraduateeducated engineers from which to choose. Moreover, since without work, most noncitizens face deportment, the tendency of this subgroup of the job-eligible population to "accept lower starting salaries" is obvious. Hey, face it, American industry is not stupid; hiring the best person for the least money is just "good business." Possibly, what has transpired over the past ten years is actually good for the country in general.... just wish we had been told the truth in such matters.

Thank you for publishing an article that tells the truth. I am currently trying to get our library to subscribe to your fine journal.

Scott R. Short Assistant Professor Northerr Mlinois University

\section{Extraction in Materials Education is Still Important}

\section{To the Editor:}

I read with interest the September MRS Bulletin. While a review of the general field of materials science and engineering education is useful, I found the omission of any discussion of minerals or extraction unfortunate. I cannot find anywhere in the issue the words "ore" or "mineral"; the word "extraction" appears to be used only in connection with Australia, and one is left with the impression that the only areas of interaction of materials science with the geosciences are in crystallography, dislocation studies, and specialized analytical techniques.

Even if one assumes that the day of metal extraction in the U.S. is past (which some scientists and engineers regard as premature), the techniques of extraction will continue to be of importance in materials recycling. Furthermore, there is a large body of work which needs to be done in the area of site remediation. In many places in the U.S., industrial wastes need to be extracted or else reacted to render them harmless. This is a hydrometallurgical problem of enormous magnitude, and hydrometallurgy is historically a major component of metallurgy which, in turn, is a component of materials science and engineering; yet one would gather from the articles in this Bulletin that MS\&E professionals have nothing to contribute.

The domination of MS\&E by persons oriented to mechanical engineering and physics may be justified by the employment and research-funding situation in recent years, and I appreciate that many of these people are profoundly uninterested in the chemical and mineralogical aspects of the field; but I would like to suggest that there is, and will continue to be, a place for chemical (and biochemical) processing in MS\&E, and it ought not to be wholly disregarded.

Michael McNeil

Nuclear Regulatory Commission Washington, DC
The MRS Bulletin invites readers to send letters to the editor. Letters must be signed and should include affiliation, address, and phone number. Short, typed letters are preferred. Mail or fax letters to: Editor, MRS Bulletin, Materials Research Society, 9800 McKnight Road, Pittsburgh, PA 15237; FAX: (412) 367-4373.

\section{ANNOUNCING}

a new opportunity for MRS Members in 1993

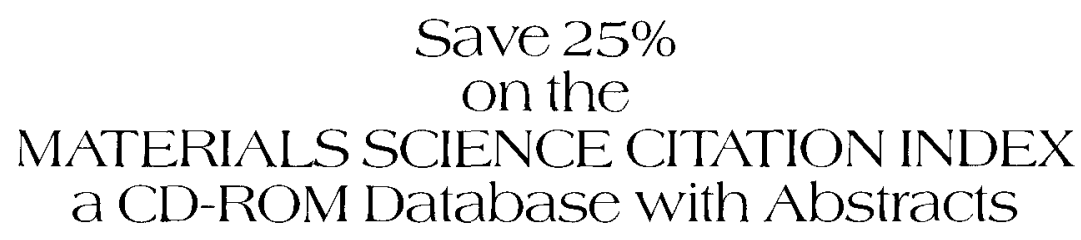

This offer available ONLY to 1993 MRS Members by special arrangement with the Institute for Scientific Information

Be sure you have renewed your MRS Membership.

For information contact MRS at (412) 367-3003

Fax (412) 367-4373 